LA-8711-P

th. 7564

Proposal

MASTER

Proposal to Produce Large Compact Toroids

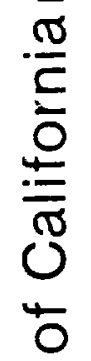

:

LOS ALAMO SCIENTIFIC LABORATORY

Post Office Box 1663 Los Alamo. New Mexico 87545 
LA-8711-P

Proposal

UC-20d

Issued: March 1981

\title{
Proposal to Produce Large Compact Toroids
}

\author{
J. A. Phillips
}




\begin{abstract}
Relatively large, hot compact toroids might be produced in the annular space between two concentric one-turn coils. with currents in the two coils flowing in the same direction, the magnetic fields on each side of the plasma are in opposite directions. As the fields are raised, the plasma ring is heated and compressed radially towards the center of the annular space. By the addition of two sets of auxiliary coils, the plasma ring can be ejected out one end of the two-coil system into a long axial magnetic field.

Reports on a preliminary experiment done in 1963-65 are included (Appendix A) together with similar work done by A. Eberhagen (Appendix B).
\end{abstract}

\title{
I. INTRODUCTION
}

It is proposed to produce relatively large, hot compact toroids which on transfer into a longitudinal confinement magnetic field are adiabatially compressed and heated. The configuration allows for ejection of the compact toroids out of the formative region.

The source of the compact toroids consists of two concentric one-turn coils, $A$ and $B$ in Fig. la, connected to a pulsed power source such that the currents in the two coils flow in the same direction. When a good conductor (the plasma) is positioned in the annular space between the coils, the magnetic field lines on each side of this conductor are in the opposite directions. As the magnetic fields are raised, the plasma is heated and compressed radially towards the center of the annular space. At the two axial ends of the plasma, 


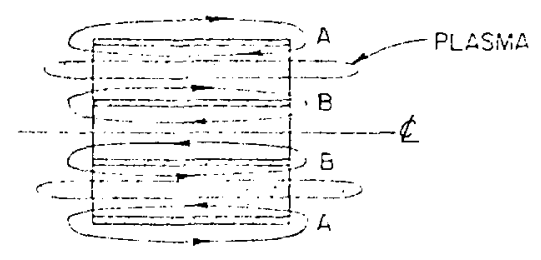

o

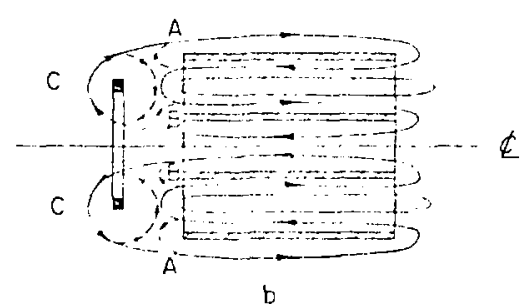

b

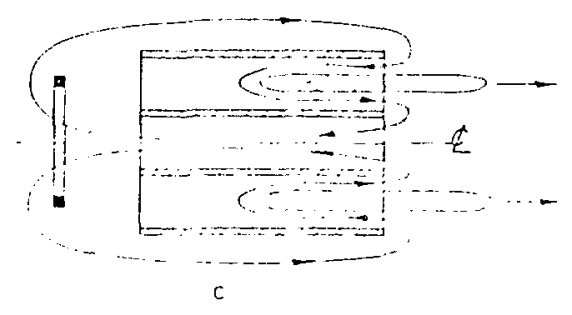

Fig. I

Two concentric one-turn coils $A$ and $B$ have currents in the same direction. In the annular space within the coils, a ring of plasma is produced by rising currents in the two coils, a. In $b$, a third coil $C$ is energized. The magnetic field lines between coils $C A$ and $C B$ are cut and retied, $c$, with the plasma ring accelerated outwards.

magnetic field lines are cut and retied (as in the reversed-field theta pinch), producing a compact toroid. At or near maximum current a third coil, $C$ in Fig. Ib, is energized with current flowing in the same direction as in coils $A$ and $B$. The fields in the regions $A C$ and $C D$ are to first order cancelled and field lines are tied around the left end of the plasma. The axial pressure on the plasma is now no longer balanced and the plasma ring is moved out of the coils to the right, Fig. Ic.

In the proposed concept the compact toroids would be moved into an axial confinement magnetic field which radially compresses the ring towards the axis with adiabatic heating. 
II. EXPERIMENTAL OBSERVATIONS

An experiment, called the "Slingshot," was designed and tested in 19631365 by Mather, Phillips, Livermore and Wittman. Siingshot was a plasma accelerator, suggested by phillips, which made use of the principle of slowly storing magnetic field energy close to or in the plasma accelerator region. A fast trigger places the system in an unstable state with magnetic field energy converted either into plasma thermal or transitational energy faster than can be delivered by conventional energy sources.

In the coil systems, shown in Fig. 2 (designed by R. Nike), the two concentric coils, radii $6.25 \mathrm{~cm}$ and $10.75 \mathrm{~cm}$ and length $7.5 \mathrm{~cm}$, were energized by a capacitor bank of $9 \mathrm{~kJ}, 45 \mu \mathrm{f}$ at $20 \mathrm{kV}$. The two coils were connected to a common header by the tapered parallel-plate transmission lines $A$ and $B$. With a rise time of $\sim 3 \mu \mathrm{s}$, the peak axial magnetic field was $<2.4 \mathrm{kG}$. Ring discharges were formed in the annular space between the coils and were compressei to a position approximately midway between the coils where the $B_{z}$ field passed through zero. Measurements of the radial component of the magnetic field showed that the plasma ring initially compressed axially toward the midplane and then expanded axially outward. A revcrse-field theta pinch was thus formed in the form of a hollow ring. The plasma ring appeared centrally located and grossly

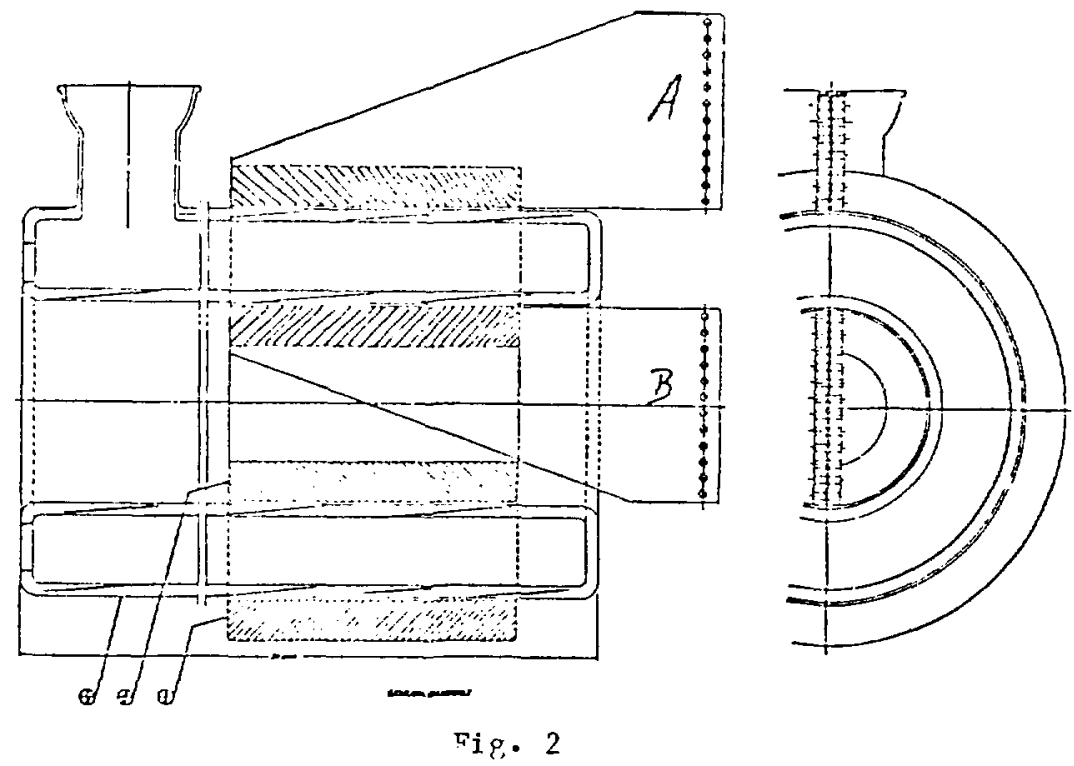

The two-coil system constructed in 1963, which tested the production of plasma rings. The two manifolds, $A$ and $B$, were connected to a common high-voltage header. 
stable. The final step in the slingshot program, to energize a coil $C$ and accelerate the ring out the coil system, was not attempted due to lack of time. The CTR-2 Progress Reports describing the experiment are included in Appendix A.

\section{ENGINEERING DESIGN}

To ensure the successful tracking of the magnetic fields it would appear that the inductances of the three currents on the two coils (two on the inner coil) should be equal, Fig. 2. This condition can be met if the two coils are driven by the same voltage source, and if

1) The three fluxes $\phi_{i}$ are equal assuring good separation of field lines in the annular region, and

2) The currents are equal on the three coil suriaces with the three magnetic ficlds equal in strength.

calculations show (neglecting end effects) that these conditions will be satisfied if

$$
r=(2+\sqrt{ } 2) a \text {, and } b=0.768 a \text {, }
$$

where $r, a$, and $b$ are defined in Fig. 3. The inductance of each of the three volumes is given by

$$
L=230.1 \frac{a^{2}}{A} \times 10^{-9} h,
$$

with dimensions given in centimeters. The coils in the early experiment apparently has been calculated using these considerations, with an $(a+b)=$ $4.5 \mathrm{~cm}$, a calculated ( $\mathrm{r}-\mathrm{a}$ ) of $6.25 \mathrm{~cm}$, whereas the experiment has $6.16 \mathrm{~cm}$. The total magnetic field energy required for a maximum $B_{z}$ field of $R_{z_{0}}$ (in $k G$ ) is

$$
U_{T}=0.874 a^{2} A B_{z_{O}}^{2} \text { joules. }
$$


If the assumptions are made, $B_{z_{O}}=20 \mathrm{kG}, A=5 a$, and current rise time is 4.71 $\mu \mathrm{s}$, the required magnetic field energies and voltages are shown as a function of length A in Fig. 3 .

The values appear to be quite reasonable; for example, for a Iength of coil A of $20 \mathrm{~cm}$ requires $20 \mathrm{kV}$, an energy of $110 \mathrm{~kJ}$, has an annular space between the coils of $7 \mathrm{~cm}$, and a zero field radius of $14 \mathrm{~cm}$.

IV. INJECTION INTO THE CONFINEMENT FIELD

As described above, energizing coil $\mathrm{C}$ in Fig. lb gives the slingshot magnetic field distribution. The unbalanced force accelerates the plasma to the right. As was stated in the progress reports, the measured force moving the plasma is at first smal1 hut increases as the right end of the coil is reached. The CT ring will then move into the confinement region as shown in Fig. lc.

If cutting and tying of magnetic field lines can be made to work, the slingshot process can be used to translate the CT ring wholly into the confinement field region, shown in Fig. 4. Here, a specially designed coil D and two small auxiliary coils $C^{\prime}$ are added. The two coils $C^{\prime}$ are used to

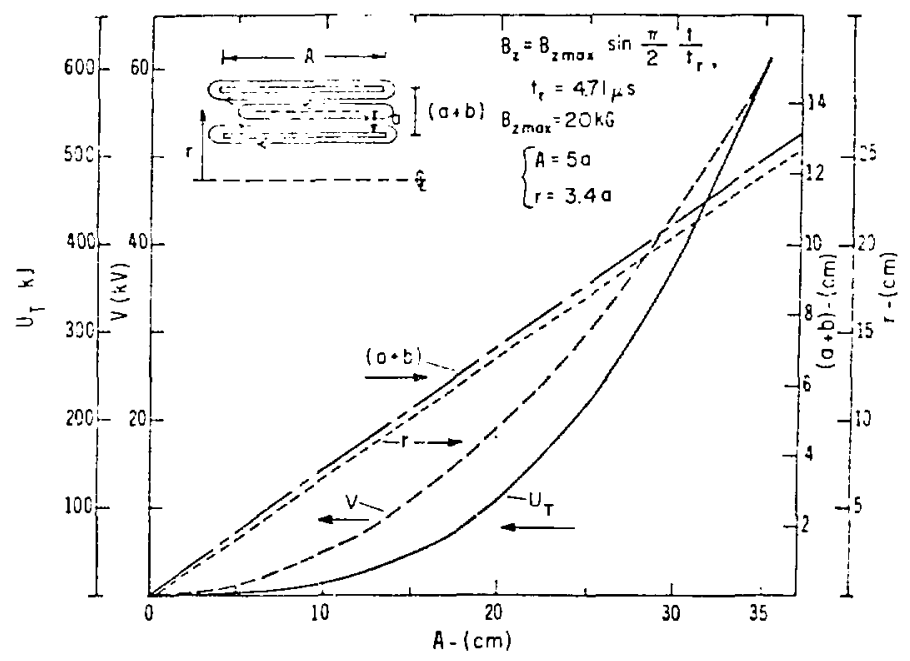

Fig. 3

The stored energy and voltage required to drive a two one-turn coil system as a function of the coil length, radius of inner coil, and spacing between the two coils. The current risetime is $4.71 \mu s$ and maximum magnetic field is $20 \mathrm{kG}$. 

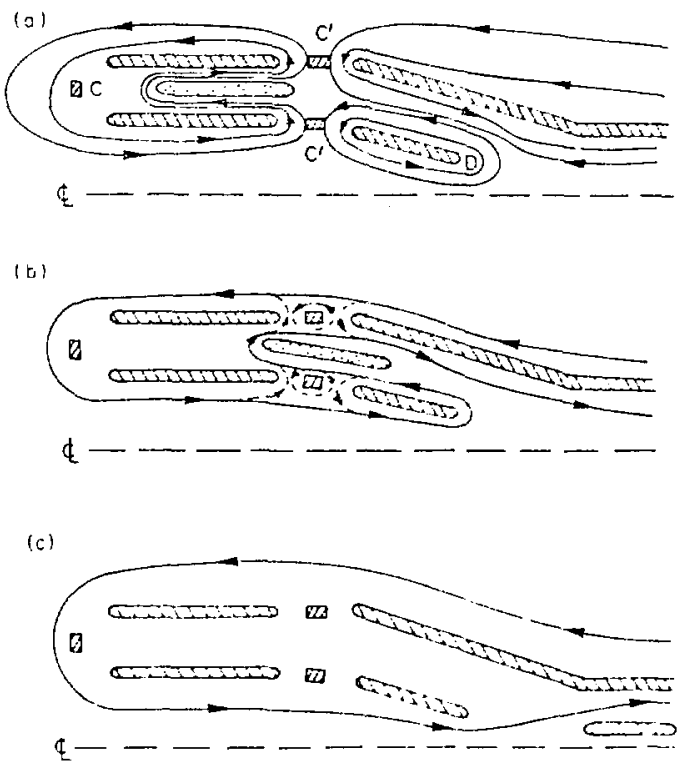

Fig. 4

Figures showing the method by which a plasma ring can be moved axially from its source (a) into a long confining magnetic field (c). Snipper coils $C^{\prime}$ cut and retie magnetic field lines extending the initial slingshot mechanism into the final field.

reconnect the slingshot magnetic field lines to those of the confining field and the coil $n$. The slingshot will then be extended to accelerate the plasma deep into the throat of the confining region. The specially shaped coil D not nnly further extends the slingshot action but also prevents the ST ring from a premature expansion to the axis. A simplification of the system is that the currents in all the coils are in the same direction. The successful operation of the device will depend, of course, on the correct timing of the currents and a matching of field amplitudes.

V. TRAPPED TOROIMAL FTELD

If a trapped toroidal field is desired in the CT, this might be done with one or two Z-pinch discharges, Fig. 5. One or two pairs of rings at each end of the ccils would act as electrodes between which axial currents flow. The currents could be driven in opposite directions creating a magnetic field azimuthally around the main axis of the colls, Fig. 5a. When the $B_{z}$ magnetic 
$(5)$
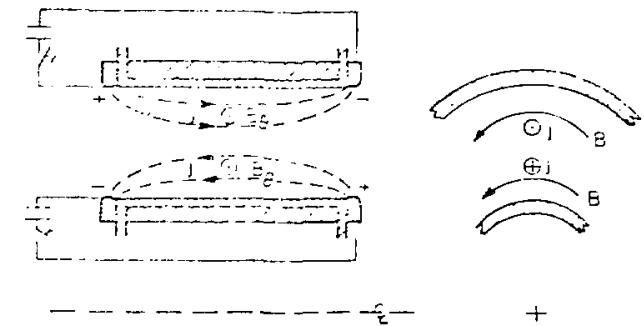

$+$

(E)

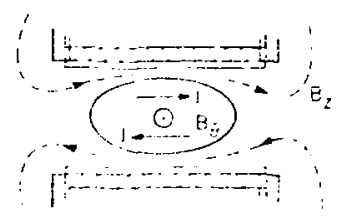

Fig. 5

Two $Z$-pinches can be added, a, to produce a toroidal field in the plasma ring, b.

field lines are cut and tied these axial currents will continue to flow, trapping the toroidal field, Fig. 5b. These currents can be driven by two capacitor bank charged with voltages of opposite sign.

Azimuthal uniformity of these axial currents may be difficult to achieie and probably would require a snal? hias field and heavy preionization. Adred features of this particular geometry are: the large effective radii of the nuter 7. pinch and close proximity to a conducting wall (the outer coil) which would yiore some stability apainst an $m=0,1$ distortions, and the complete stability of the inverse 7. pinch on the inside. It may turn out that only one of the 7-pinches will be needed,--diffusion of the magnetic field of the inverse \%-pinch into the C.T ring, being sufficient. This pinch has the desirable feature of being complecty MH! stable.

VI. DISCIISSION OF PROPOSAI.

rirossly stable compact toroids have been formed in the annular space between two concentric coils. If these rings can be transferred into a confinement region, a hot CT could be available for consideration in a fusion reactor. 
Possible advantages of the concept include:

1) Large compact toroids could be formed with their size limited only by plasma hreakdown and coil voltages.

2) Formation of the compact toroid can be controljed by independent variation of the two opposing magnetic fields. Also, the $B_{z}$ magretir field at the wall need not pass through zero as in the field-reversed theta pinch, which may reduce wall impurities brought into the $\mathrm{CT}$. In addition, it has been pointed cut (Rulon Linford) that the proposod genmetry allows the magnetic fielis to be raised relatively slowly since the Poynting vector at the walls always points radially inward. The compact-toroid formation could then take piace over a relativiy long. time and more conventional low voltage power supplies rould be used.

3) An effirient mechanism of ring acceleration out of the coils into the componeit region is aynilable.

4) Thr officiancy of energy transfer could be high with most of thr. magnetic ficld energy being, transferter into plasma thermal onerav, compact toroid energy or ring translational energy.

5) Adiabatic heating in compressing the CT ring towards the ayis could he larye.

5) The connection by line tying to the confinement region is facilitateri by the magnetic field of auxiliary coils, $C^{\prime}$, in the region to the right of the coils, Fig. la.

There are questions that need to be resolved:

1) The ring formation requires a strong pre-ionization of the plasma to separate the oppositely directed magnetic fields as was found in the cxperiment. At low deuterium pressues can this be done?

2) In the translation of the ring, out of the coil system will the placr:s ring remain stable?

In the initial concept there is no tornidal magnetic field in the C.T. If this field is desired, an axial current through the plasma may be applied between electrodes at each end of the convective coils. One of these? pinches, an inverse pinch, would be completely MHD stable. 
vote

In discussing these ideas with fulon Linford reference was made to work by A. Tberhagen, rarching, FRC, in which CT rings were formed in the annular region between two coaxial theta-pinch coils. (A reprint describing this work is included as Appendix B). Plasma temperatures and densities were low, $\sim 20$ eV and $5 \times 10^{15} \mathrm{~cm}^{-3}$, and lifetimes of the plasma configuration were limited to $1 \cap-30 \mu s$. These plasma lifetimes were up to ten times larger than the characteristic growth time for rHD-instabilities.

Eberhagen's work supports the early slingshot results in that compact torvids can be made between two concentric theta-pinch coils. Also the lifetimes of the CT rings, even at the very low temperatures of $\sim 20 \mathrm{eV}$, may be sufficiently long to allow transport to a confinement region where the plasma stability should be much greater.

Appendix A

GROUP P-14 MONTHLY REPORT, JAMUARY 20, 1964

JAMES A. PHILLIPS, GROUP LEADER

VIII. A plasma accelerator is proposed in which energy is first stored in magnetic energy close to or in the plasma accelerator and then converted into particle energy by a trigger mechanism. It is hoped that the energy conversion will take place faster than can be handled by conventional energy sources.

VII I. PLASMA ACCELERATOP - "SLIMGSHOT" (Mather, Livermore, Phillips)

It has seemed to one of us ( $J$. Phillips) that if higher efficiencies of energy transfer are to be achieved in plasma accelerators the inherent slowness of practial energy sources must somehow be circumvented. The suggestion is made that this might be done by first converting energy into magnetic energy close to or in the plasma 
accelerator itself at a relatively slow rate. Then this is completed, it might then be possible to trigger the system into an urstable regime so that the magnetic energy can be converted either into thermal or translational enerpy of the plasma considerably faster than can be handled by an entire energy source consisting of switches, capacitors and cables. A number of examples can be cited: 1) in the orthogonal pinch and Scylla, energy is slowly pumped into the reverse magnet ic field and then by some field mixing mechanism (an instability?) this enorgy is trarsferred quickly into particle energy, and 2) in the hydromarnetic. gur. Lasma accelerations occur as a result of the magnetic enerpy strort between tho electrodes inducing large voltages when the current sheat'; collapses off the end of the center electrodes driving tie plaswa invard and forwarl at high velocities.

A plasina accelerator which may make use of this idea is shown in Fig. A-l(a). The two concentric coils $A$ and $B$ are driver hy two indepenrient power supplies having identical ringing frequencies witl, tho currents in the two coils flowing in the same direction. If a pond conductor (the plasma) is located in the annular space between the tw coils, the magnetic field lines on each side of the conductor will he in opposite directions. If the plasma magnetic field interfaces are stable, the plasma will be radially compressed by the magnetic fielda. At peak currents when the energy is in the magnetic fields between the cirils and plasma, a third coil $\mathrm{C}$ between the coils and plazma is energized by passing through it a current in the same direction as that flowing in the coils $A$ and $B$. Then this is done, the magnetic fields in the regions $A C$ and $C D$ are to first order cancelled, with the field lines on eich side of the plasma joining togelicr around the end of the plasma. At this point the pressures on the plasma are no longer balanced and the plasma is accelerated to the right.

This scheme may have advantages over the conventional conical orthogonal or 0 -pinch as shown in Fig. A-2(a). In this geometry axial acceleration is by the $\bar{J}_{\theta} \times \bar{B}_{r}$ force, where $\bar{J}_{\theta}$ in the azimuthal current density in the plasma and $\bar{B}_{r}$ is the radial component of the magnetic field. In the proposed geometry, Fig. $A-2(b)$, axial acceleration is also given by $\bar{J}_{\theta} \times \bar{B}_{r}$ but here $\bar{B}_{r}$ is the full magnitude of $B$. A second and important advantage may be that in the proposed geonetry the acceleration 
may be initiated at maximum current. In the conical pinch the plasma begins to move away from the coil almost immediately and will be at a distance away from the coil where the acceleration is reduced at the current maximum.

A very preliminary test of some of these ideas was nade about one year ago. Two coils vere energized separately and the impulse given a copier cylinder located between the coils measured. Data taken with the two currents in the same and opposite directions as a function of axial position of the copper cylinder are shown in Figs. A-3(a) and $A-3(b)$. We see, Fig. A-3(a), that with the currents in the same directions the impulse is larger than with each alone and considerably larger than when the currents ar in opposite directions, Fig. A-3(b). We also see that the impulse is preatest when the copper cylinder is located just at the entrance of the two coils. This is expected since the change in inductance of the coils witt axial position of the cylinder is here a maximun

A test c: the complete geometry is too complicated for a first step. The stablity of the plasma is uncertain and the plasma may rip and shred with incomplete acceleration. The modification shown in Fig. A-4 may give some preliminary information on the performance. Here the two coils are in parallel and connected to one energy supply (the geometry may be thought of as a toroidal pinch in which one side of the primary winding, has been removed). The acceleration mechanism here cannot be triggered bit will be determined hy the seometry. An initial force on the plasma will he produced by the current in the "hack-strap," the force drops as the plasma moves axially to the right and then increases as the plasma emerges from the coil. Whether or not optimum acceleration can be obtained will be determined by the length of the coil, plasma mass density, and amplitude and period of the primary current. A coil system has been constructed with $\ell=15 \mathrm{~cm}, R$ outer $=8.6 \mathrm{~cm}$ and $R$ inner $=5 \mathrm{~cm}$. The orthogonal pinch condenser supply, $150 \mu \mathrm{F}$ t $20 \mathrm{kV}$, will be used.

\section{A-16 BANK INSTALLATION (Holm, Schofield)}

A moderately fast capacitor bank system has been designed and is being installed in A-16 for the dense plasma focus and "slingshot" experinents. 
The system when complete will consist of forty 14.2- $\mathrm{F}, 20-\mathrm{kV}$ Tohe Deutschman capacitors with a vacuum sprek gap and vacuum crowbar gap on each. This bank will be capable of being max charged to $30 \mathrm{kV}$ in about 200 usec from a Marx capacitor bank.

The source inductance for this system will be $\sim 4 \times 10^{-8}$ w with an energy storage of about $100 \mathrm{~kJ}$ at $20 \mathrm{kV}$ and $225 \mathrm{~kJ}$ at $30 \mathrm{kV}$ (in the crowbarred mode).

"MARCH 1965

IT. "SILNGSIOT" ACCFI EPATOR (Mather, Wittman)

A small "slingshot" accelerator is now being studied which consists of a $12.5-\mathrm{cm}$ inner and $27.5-\mathrm{cm}$ nuter diameter coil system with a length of $7.5 \mathrm{~cm}$. A $45-\mu \mathrm{F}$, ? $0-\mathrm{kV}$ capacitor bank produces peak currents of $\sim 450 \mathrm{kA}$ with a rise time of $3 \mathrm{jsec}$. Preliminary measurements show that (1) a magnetic field zeru exists approximately centered in the annular reginn between the drior coils before a plasma is generated and (2) with argon or helium gas filling, a plasma ring discharge is observed to collapse in radius to the equilihrium radius. From end-on integrated light photographs, the plasma ring appears centrally located and grossly stable.

Time dependent visible light photographs of the formation and collapsing stages of the ring discharge have been made in helium at pressures of $\sim$ i00, 300, and 600 millitorr with RF preexcitation. The initial formation of the ring discharge is strongly affected by RF preexcitation; without RF, a multiplicity of ringed filaments is seen. This suggests the need for very strong preexcitation.

Some gerieral comments follow:

1. At pressures of $\sim 600$ mtorr the ring discharge collapses to a position approximately midway between the walls of the vacuum vessel $\left(\Delta \mathrm{r}_{0} \sim 4.5 \mathrm{~cm}\right)$ and reaches a minimum cross section $\Delta r$ of $\sim 1.2 \mathrm{~cm}$ in $1.4 \mathrm{\mu sec}$. The ringed plasma cross section remains approxinately constant during the remainder of the current rise time of 3 usec.

2. At a pressure of $\sim 30 n$ mtorr similar behavior is observed except that the plasma collapses to a $\mathrm{Ar} \sim 1.2 \mathrm{~cm}$ in $\sim 1 \mathrm{usec}$ and then 
gratually expands to $1.5 \mathrm{~cm}$ during the continued rise of the current.

3. At : Do motor a mininum $\Delta$ r occurs at $\sim 0.8 \mu \mathrm{sec}$. For $t>0.8 \mu \mathrm{sec}$ the plasma ring dimensions steadily increase. At peak current the plasna ring fills the entire annular region $\Delta r_{0}=4.5 \mathrm{r}$.

The effect of the feedpoint, mainly its massiveness, is clearly observed under all operating conditions. This shows up as an ont-of-roundness of the plasma ring in the feedpoint region. This effect becumes quite distinct near peak current time. The out-of-roundness effect appears noticeable at the lower pressures at early times - as the pressure is increased the effect, although still there, is less dramatic during the continued rise of the current.

Preliminary magnetic field measurements show that the current in the plasma ring is approximately one-half the totai primary current. The plasma ring at first collapses radially and then begins to spread along the axis of the tube. The axial spread of the plasma ring is expected since no large axial restoring forces are present in this type of accelerator system.

The next step is to determine whether the ring discharge can be ejected from the plasma accelerator by the use of a subsidiary single turn coil $\sim 17.5 \mathrm{~cm}$ diameter located at one end of the drive coil system.

IV. "SLI IGSHOT" ACCELERATOR (Mather, Wittinan)

Magnetic Probe Measurement

A radial distribution of the $\mathrm{B}_{z}$ magnetic field taken at the midpiane of the "slingshot" accelerator system shows that a ring, discharge starts near the outer and inner surface of the inner and outer coil, respectively; the plasma fills the annular region, $\Delta r_{0}=4.5 \mathrm{~cm}$ between the coils at $t=0$, and proceeds to pinch toward the equilibrium radius with time. A schematic of the "slingshot" accelerator is shown in Fig. A-l. The radial extent $\Delta r$ of the plasma discharge reaches a minimum $\Delta r \sim 1 \mathrm{~cm}$ at peak current ( $t_{\text {peak }} \sim 3 \mu \mathrm{sec}$ ). The plasma ring centers finally about a radius midway between the coils at approximately the same radius where the vacuum $B_{z}$ field passes through zero. For slightly higher bank voltage, $12.6 \mathrm{kV}$ instead of $9.4 \mathrm{kV}$, and for the same helium pressures $\sim 100$ mtorr, the ring discharge compresses at a faster rate and reaches 
approximately the same $\Delta \mathrm{r} \sim 1 \mathrm{~cm}$ in ? usec. The jump ir the $\mathrm{h}_{2}$ magnetic field across the plasma ring, a measure of the plasma ring current, rollows the applied voltage.

Measurements of the voltage on the coil system and the rate of change of current $d i / d t$, neglecting resistance, should yield a value for the inductance of the system with time. The analysis indicates an almost Linear increase of the inductance with time.

Measurements of the axial distribition of ${ }^{{ }} \mathrm{r}$ at approximately the equilibriur: radius show generally a linear change in ${ }^{B} r$ from the midplane of the rrii system to the face of the coil. The probe senses the ${ }^{B} r$ field component of the plasma ring rlischarge. The interesting point is that the B $\mathrm{r}$ field component increases steadily for $\sim 2$ usec throughout the $z$ distribution and then begins to decrease slowly at first and then morf rapidly during the continued rise of the driving current. These results suggest that the plasma ring discharge is compressed radially at first as the current incruses and then at w2 usce, the ring discharge begins to spread axially. Since no axial restraining forces act on the ring. discharges, these experimental results arr not ton curprising.
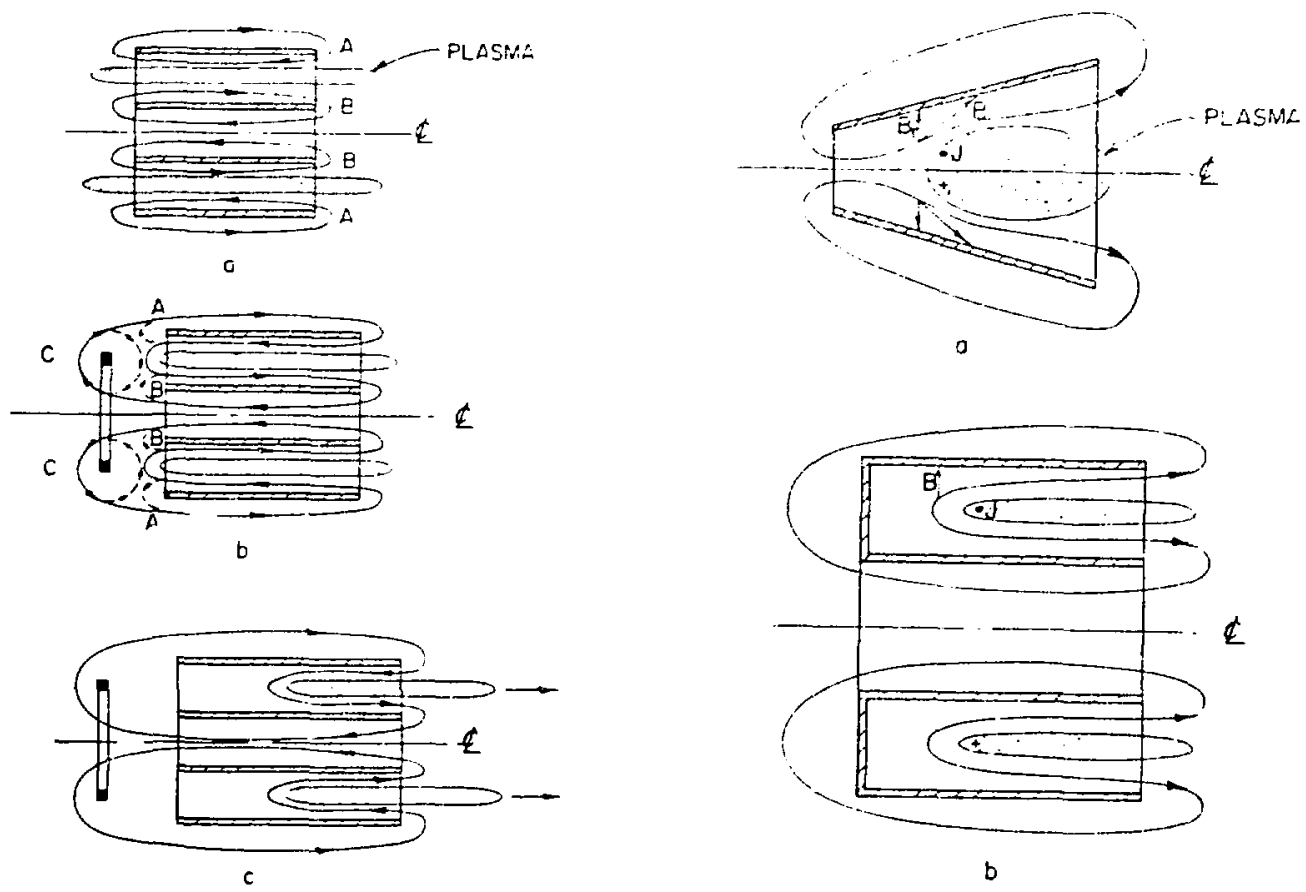

Fig. $A-1$

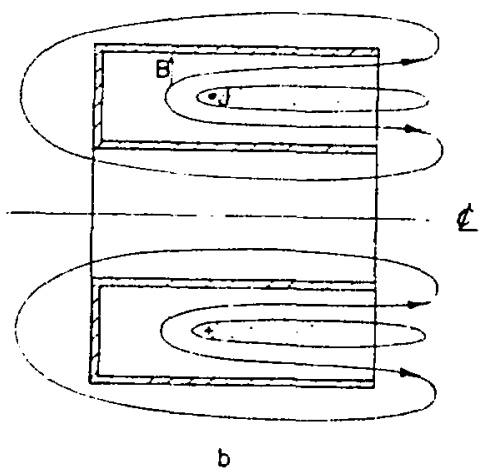

Fig. A-2 


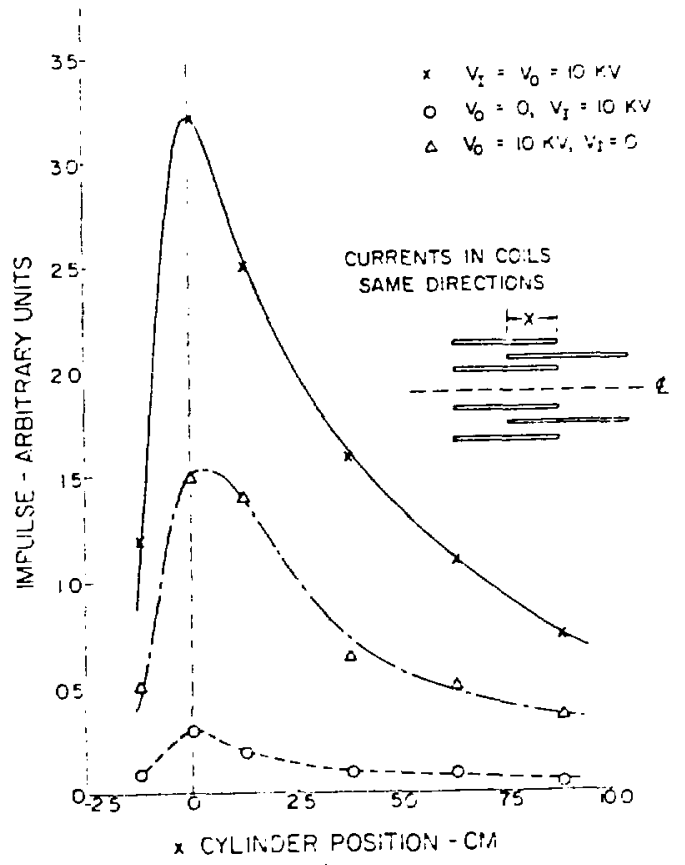

fig. $\Lambda-3(a)$

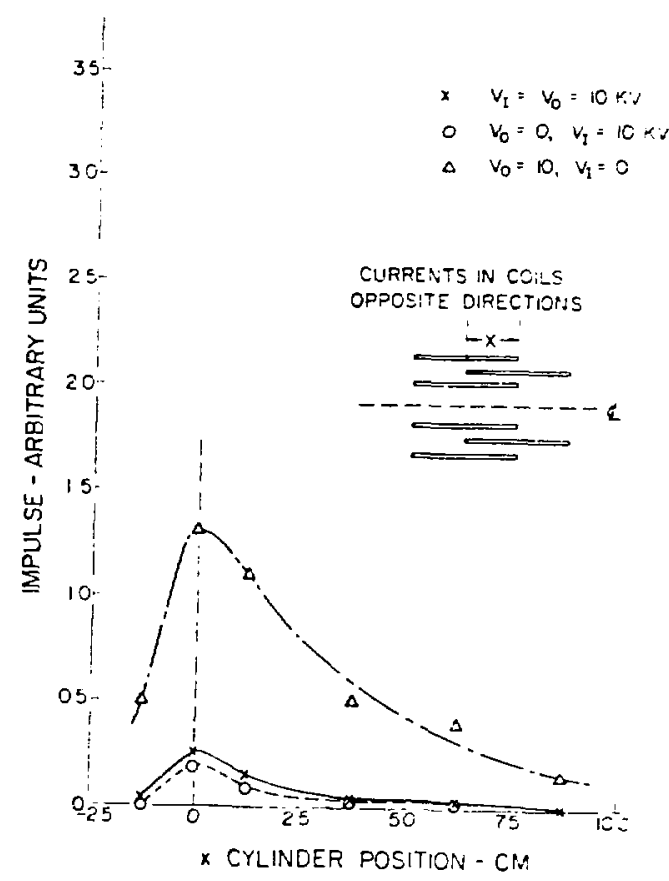

Fig. $A-3(h)$

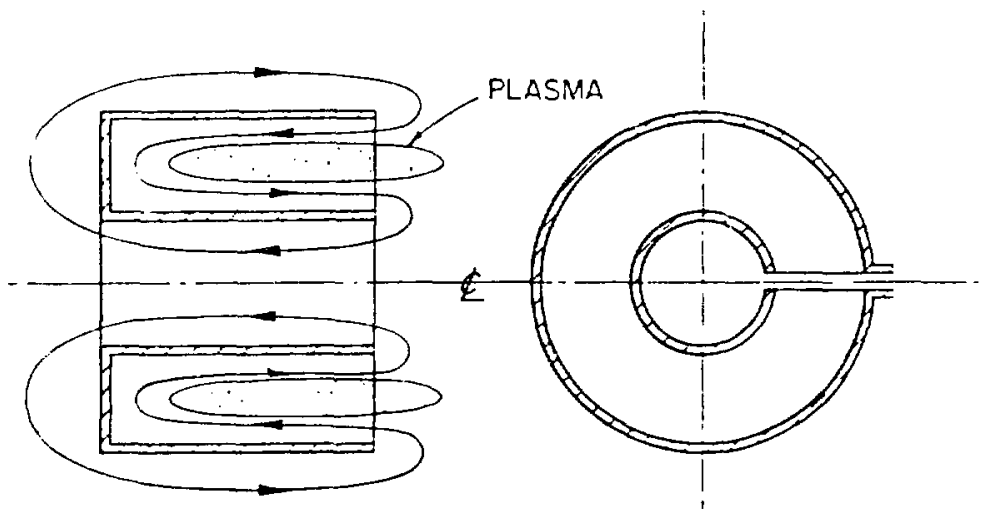

Fig. $\Lambda-4$ 


\section{Appendix $B$}

Exporiences From Field-Reverso' Pinch Exemiments in Garching

Sy A. Ekurhagen, Inctitut Fij Plosmarhysh, Gorchinz, Germony

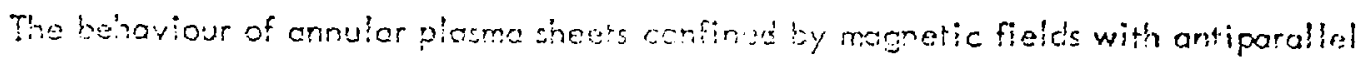

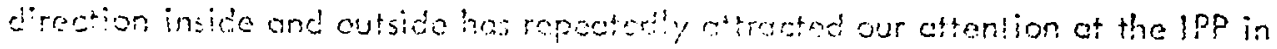

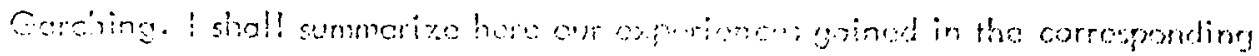

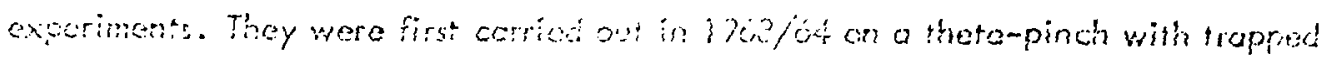
ontipard!ei mognetic field (1). It was intenc'ses then to study the potentialities of shis configuration for by-passing the ond-ioss problem in lineor theta-pinch devices.

The potuction of the annutar plasm configuration in the theta-pinch roised no particuler poblems.

a)

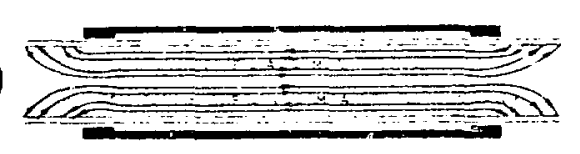

b)

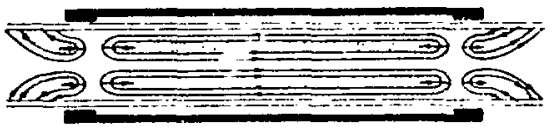

c)

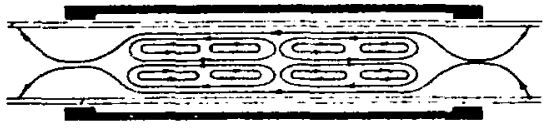

d)
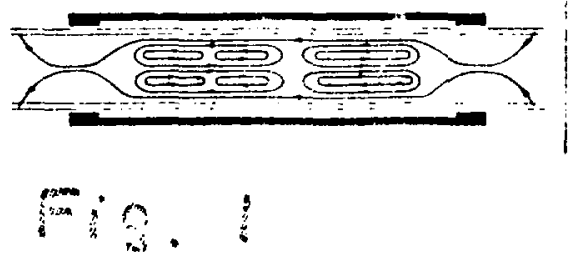

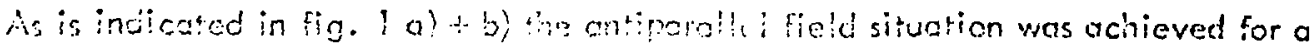

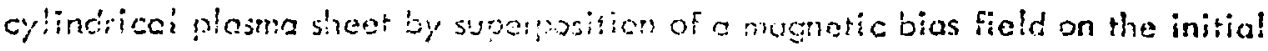


proionized plasma and by sterting the main theto-ninch discharge with reversed firect:on. Exen after start of the discharge (i.e. within 1/2 used joining of the antiparallel field lines occurred in the vicinity of the coi! ends with the result that the two exterior parts of the plasma were expelled out of the coil region. Slight magnetic mirrors at the coil ends (mirror ratio: $B_{\text {mirror }} / B_{\text {coil }} \approx 1.2$ ) improved the reproducibilitiy of the magnetic field line reconnection cartsiderably.

The remaining annular plasma configuration contracted towards the midplane of the coil under the action of the enclosing field lines (fig. $1 b$ ). The contraction ratio varied between about $0.3-0.8$ depending on the discharge parameters chosen. This initial phase of the antiparallel field situation has been studied in detail (2). These investigations confirmed a collection factor of close to unity for the axial contraction wave indicating a well established separation of the axially confined plasma from the regions towards and outside the coil end.

After this straight-foreward initial phase of plasma annulus production, however, the hollow cylindric configuration in general was unstable. As Bodin in Culham had aiready observed abost one year before (3), the annular plasma column normally broke up along its axis into several rings, which sometimes moved in the axial direction and in part even recombined, when they met (fig. $1 c)+d$ )).

This behaviour was identified by Bodin as a tearing mode instability which was predicted by Furth, $K$ illeen and Rosenbluth (4), (FKR), to occur as one type of resistive instability in the antiparallel plasma sheet situstion. Bodin claimed agreement of his experimental results with FKR-theory with respect to the growth rates (derived from the times for break up of the annular plasma column) and with the corresponding predicted wavelengths (number of observed rings).

Our experiments, however, seemed to indicate growth rates for the tearing modes reduced by at least half an order of magnitude as compared with FKR-theory. As an examp!e we see in fig. 2 a side-on smear picture of such a field-reversal pinch discharae, taken through a line of holes in the coil parallel to its axis and showing 
the time dependent axial behaviour of the plasma. The proper time scale can be tcken from the dj/dt-slope on top. No crewijar was applied in this early experiment. In this excmp!e only the axial contraction of the plosma column occurred, but the

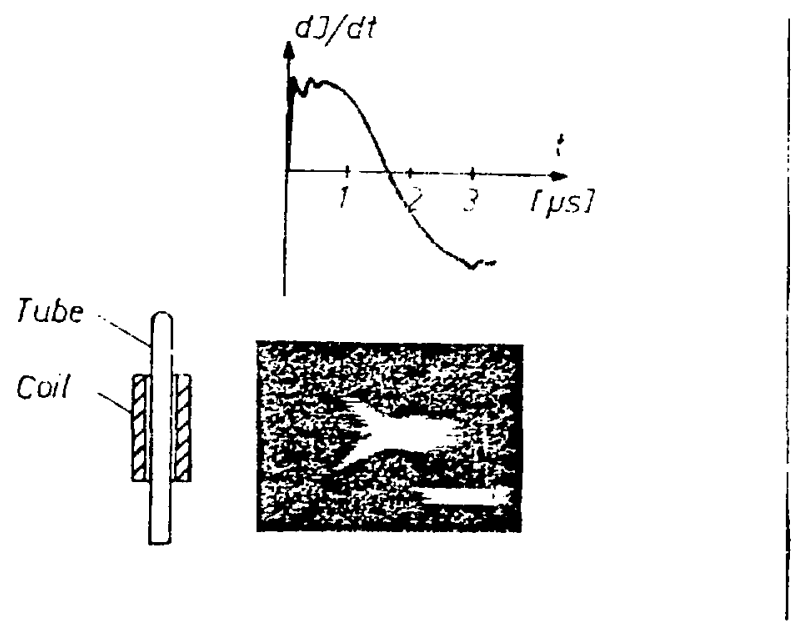

$$
\lim 2 \pi
$$

tearing instabilities were obsent. Actorting to Fkn-thery they should have oppected at bout 1,2 fuse. I should mention thot this non-ropearence of the tearing modes only tappened in porticularly cleon dischorge. Otherwise - as is shown on fig. 3due to the 'ower piama tempersture the jecmo onnulus did break up into several rings within the !me of observation (fig. 3 !.

Another interesting result of these carly experinents wos the observation that the development of teoring instcibilities could be trigered by certain arificial perturbotions. It is shown in fig. 3 thet such partubetions moy be probes radially inserted

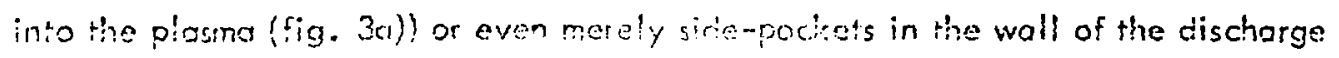

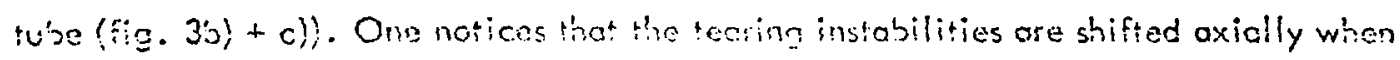
tho side-reochets ore risu displocod in z-ritestom. 
Cospis of the controdicting resuis - jout the tearing mode growth retes it was teit

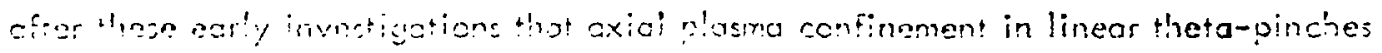

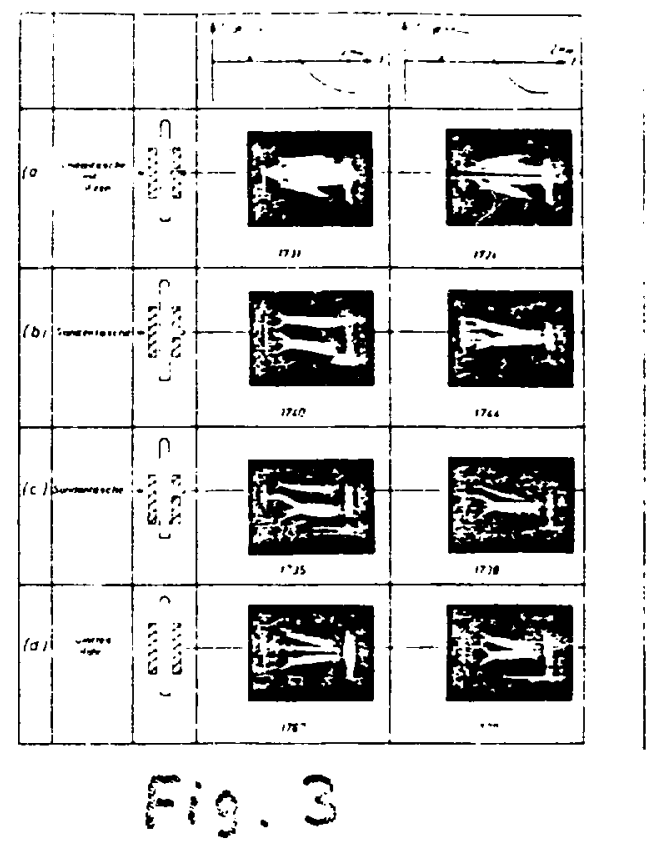

with help of fielo-reversa! was unmerasoble zecouse of these tearing mode instajilities.

Nevertheless, during the following years this antiparallel field configuration was repeabed'y established at differant bloratories (5) - (7) in order to clorify the cortrazicting experimental resulis mentioned conceming the tearing mode growth reter. In our opinion, though, no clear onswer yeas presented.

Since the quation had besn raises in this context that sur investigations might have suifered from the occurrence of a strong axist contraction and from a relatively short exporimentol time scole we took up this problem ogain in 1970/71 (\$). These exporiments were done an a largely ingrove theta-ninch with a crowbar installed anc' with some further madifications in the electrieal eircuitry in order to eliminate the corresponding crowsar oscillations. As can be seen from tig. 4 a fairly constant slope of the magnetic field! in the coi! was cchieved after the initid peak. For the exconole presented in tia. 4 we see further: 
.. a sidreon smear picure shewing the ime dependent axial behaviaur of the prowered plosma bollow sy!inder

... an end-on smear pichure semenstrating the raclial development of the plasso arnesiss

and finally a diomoznatic signo! which meosured the diamegnetic flux

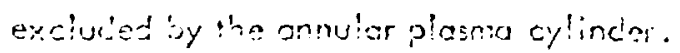

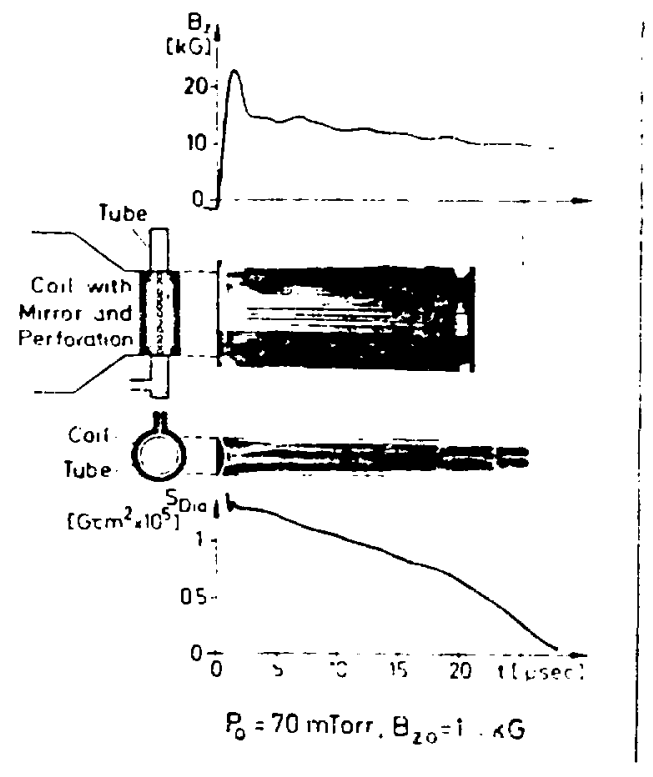

\section{Eis.}

We notice from fig. 4 that after the fost plasma compression and some radial oscillations the well established plasma aniulus contracts moderately in the axial direction with some small axial oscillations occurring. During the whole time of observotion, i.e. for obout 15 usec in the example presented, no indication of a tearing mode was detectaste. According to the Fkn-theory growth times of about I prec were expected for the presant case.

After this period, when the plasma existed in a quiet state, the annulys was alwoys destroyed by a gross plasmo instability. With the help of end-an frnming pictures this instability was easily identified os an $m=2$-like rotational mode. 
Similor results were obtained for all plosma parameters investigated. Stobility of the produced plosma annuli were observed for timns which were longer than the theorelicully prect:ond growth times for tearing instabilitias by at least an ordor of magnitude. Fint?y, howaver, the plosmo hollow cylinders were aivays destroyed by rotational instoditities.

Soverol effects were consiciered to give on explanatian for the enhonced stability o'serych. lt was showen, for instance, that this was not dure to wall effects, inertio efrects or to too short a pinching coil.

A very instructive exporiment finclly offered a possible explanation. It was shom

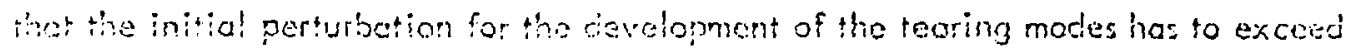

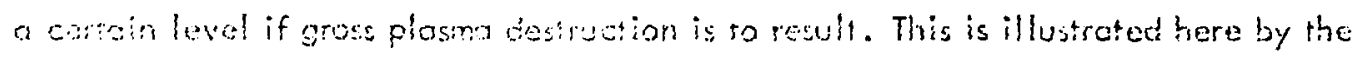
wamplown in fig. 5.
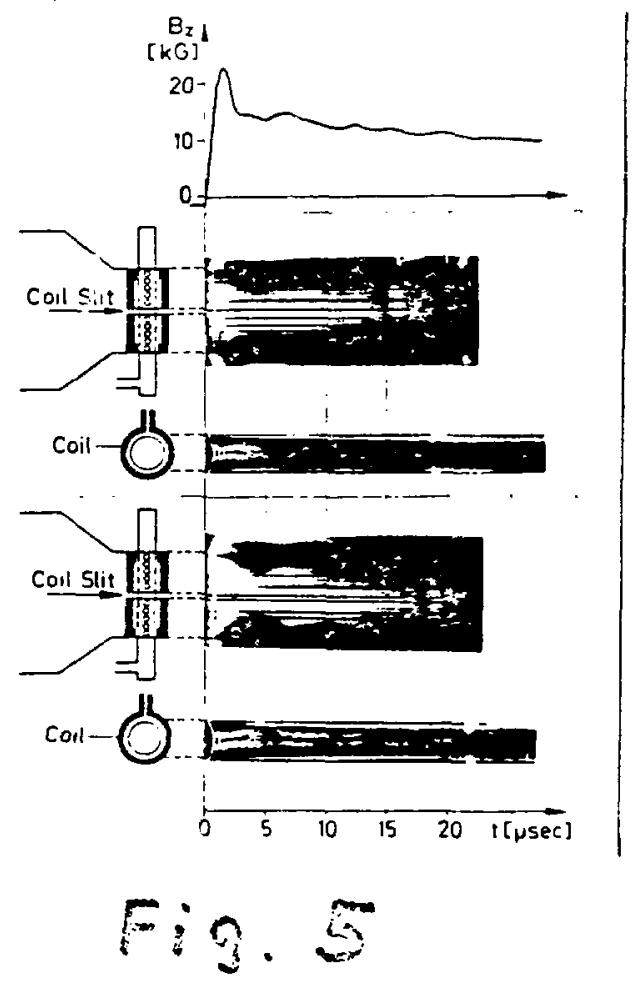

As an initic! perturbation - which in the ecrlier experiments were, e.g. , the sidepockets in the glass tube - here served slits of varying widths in the theta-pinch coil. 
The inhomogeneity of the mognetic field produced by these slits should have been experienced by the plasma in its early phases. A slit width of $1.5 \mathrm{~cm}$ in the lower excrulle:

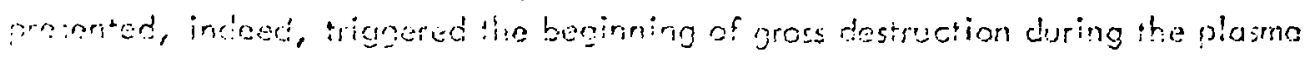
comprasion pives. This destrustion indicoted a behoviour charactoristic of that of

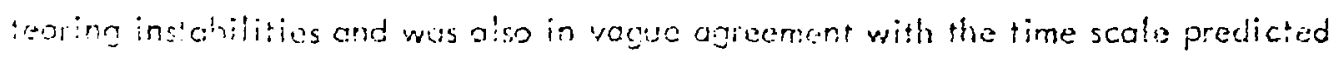

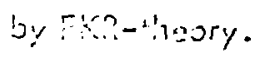

It is clso sesen in fig. 5, however, tha? this gros behaviour vanished ofter completion of the contraction period, and a stchlo and axially homogeneous plesno vas asteblished once moro lesting until the ontest of the plasmo rotationel instobilities.

Afer this result the enthanced stability observed wes thought to be due to a stctilizing $=" s=$ coirolated with the plosmo biction. The potentiol of this stabilizing effect

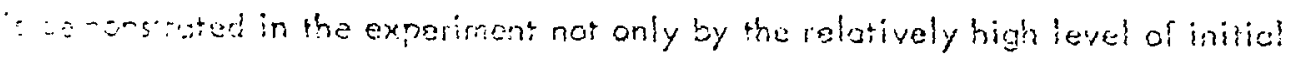
$\because \because$ aston needed for a visible gross clestruction of the plasma annulus, but even $-\because=5$ sectacularly by the foci, that atter the end of the contraction phase a single zasn = nnulus was re-established with spatial homogeneity which remained stable w'? the enset of the rotationa? instabilitis. Apporently this stabilizing anechanism could even override the resicual disturbances left over from the contraction phuse.

I Uus mention in this context thet colculations have been carried out by Kolek in Liflich, Germany (9) about the stability behaviour of rotating field-reversa! pinches. A stabilizing effect on the tearing mades was indeed observed in the colculations for rotating plasme annuli after proper considerction of the appropricte Hall-current terms.

Irrespective of this suggested correlation with the plasma rototion the surprisingly good stability behaviour of the field-reversa! pinch agsinst resistive tearing modes at this instant gave rise to reconsider the chances of this configuration for establishing oxial confinement in linear devices. One motivation for doing so acimittedly were the obvious advantages inherent in this configuration for fusion devices in case of sufficient stability. 1 just mention here its simplicity, no problem with plasma 
egullibrium, high plasma-B and the axid accessibility of the configuration which possibly could be utilized to relieve the thermal and rediation load problem of the first wall. A further point in this respect is the existing possibility to make profit c. the cxiat comrossion in addition to the rodial one for plasna heating as is being done since 1973 by the kurtmulloev group at the kurclatov institute in Moscov (10). Another reason for the reconsideration of the field-reversal pinch was its relationship with the Belt-Pinch experiments underway at Garching at that time. In fact, the field-reversal pinch is topologically eruivalent to a Belt-Pinch with purely poloidal magnetic field or with a strict $(q=0)$ - Belt-Pinch with a small aspect ratio. It was of interest to achieve some knowledge about this extreme case. Tearing modes were not considered to be too restricting in a properly designed experiment, even at the absence of additional stabilizing effects. This optimism simply originated from the scaling of the tearing mode growth rates with sheet thickness $\delta$ and plasma temperature. In the collision-dominated case FKR-theory predicts for the fastest srowing mode:

$$
\tau_{\text {colldom, fastest }} \approx \frac{\delta(\mathrm{cm})^{3 / 2} \cdot \mathrm{T}_{\mathrm{e}}(\mathrm{eV})^{1 / 2}}{3} \quad \text { (usec) }
$$

which e.g., for a fusion plasma (if collision-dominated, $\delta=100 \mathrm{~cm}, \mathrm{~T}_{\mathrm{e}}=10^{4} \mathrm{eV}$ ) would result in growth times as much as $0.03 \mathrm{sec}$. (In the collisionless case Laval \& Pellct predict (11):

$$
\left.\tau_{\text {colless }} \approx 10^{-11} \frac{\mathrm{N}^{3 / 4}\left(\mathrm{~cm}^{-3}\right) \cdot \delta(\mathrm{cm})^{5 / 2}}{T_{e}(\mathrm{eV})^{1 / 2}}(\mu \mathrm{sec})\right)
$$

Tearing modes can, so to speak, be scaled away by choosing appropriate sheetthicknesses.

If the time scale of the configuration then is expected to be no longer determined by tearing mades one must recall, however, that the field-reversal pinch may also be considered as a toroidal z-pinch with highly elongated cross section. The corresponding wellknown MHD-instabilities are, therefore, likely to occur, but 
nothing was known from theory about their behaviour as a function of aspect ratio and elongation. In the limit of high aspect ratio and high elongation the configuration approaches the sheet-piach and this is even stable in ideal MHD-theory (with no gravitational effects).

From the experimental point of view it was thus very attractive to produce such - Poloidal-Field (PF) Belt-Pinch configuration with proper sheet-thickness $\delta$ and try to octually observe its MHD-stability behoviour. In order to prevent plasma rotation from influencing these features the moment of inertia of the produced plasma annulus had to be as large as possible.

The plasma was, therefore, produced between two coaxially arranged theta-pinch coils as shown in fig. 6 (12), (13). These were connected in parallel to a $100 \mathrm{kJoule}$

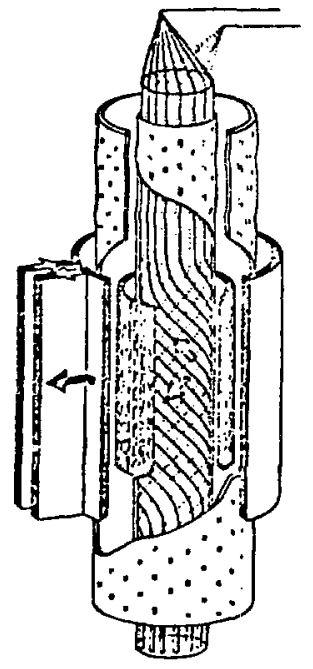

a

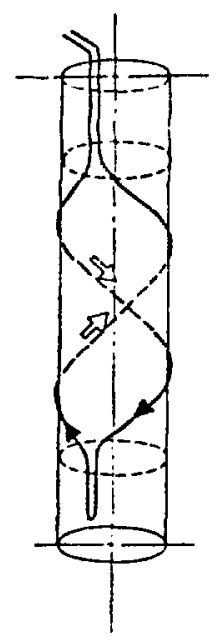

b

\section{Fig. 6}

capacitor bank and had a length of $75 \mathrm{~cm}$ and radii of $R_{i}=8.5 \mathrm{~cm}$ and $R_{0}=21 \mathrm{~cm}$, respectively. In order to achieve large sheet-thicknesses the discharges were generally crowbarred shortly after completion of the implosion phase. Consequently, 
the plasmo temperatures and densities were relatively low, about $20 \mathrm{eV}$ and $5 \cdot 10^{15} \mathrm{~cm}^{-3}$, respectively. Weak toroidal magnetic fields could be superimposed to the plasma by passing a current through o rod along the z-axis (this rod, however, is not shown in fig. 6).

An example of the computed field pattern for an equilibrium position of the plasma is shown in fig. 7 , which also contains the approximate dimensions of
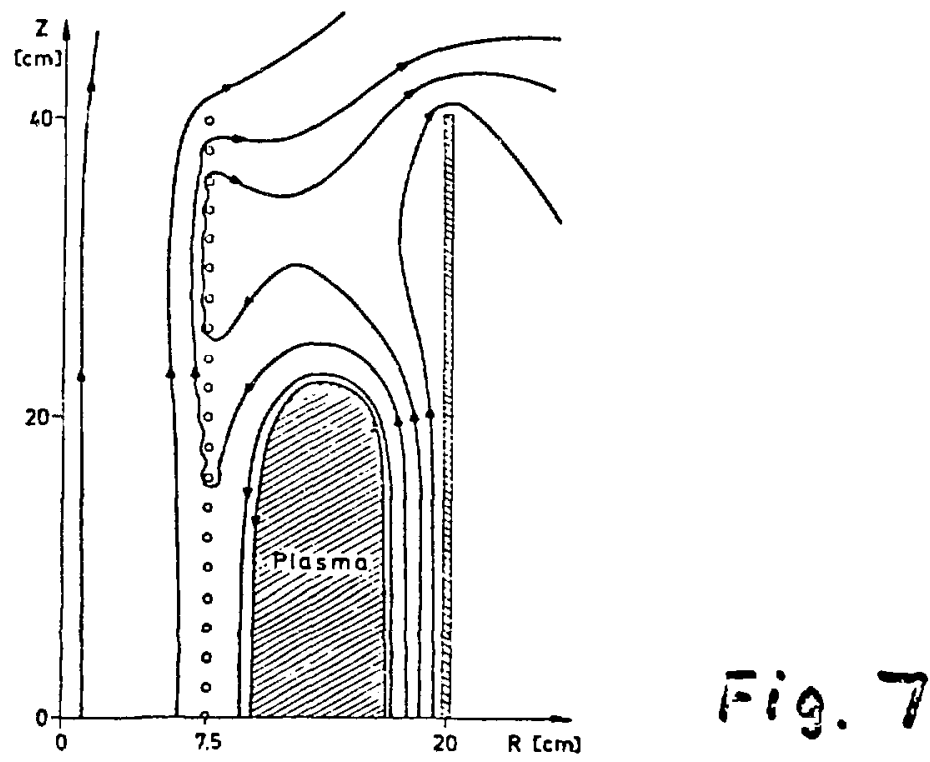

the coil system. The plasma annuli were produced in the experiment at filling pressures between: $10 \mathrm{mTcrr} \leqslant p_{0} \leqslant 70 \mathrm{mTorr}$ and had aspect ratios $(R / a)$ between 15 and 5 and elongations between 60 and 20 .

One typical example of the radial structure of the plasma is presented in fig. 8. The plasma parameters show, $n$ in this picture were derived from holographic interferometry and inserted probes, whereas the temperature was inferred from pressure balance.

The lifetime of this plasma configuration was limited to 10 to 30 usec by slowly growing disturbances which are illustrated in fig. 9. In this example the end-on smear picture shows the radial performance of the plasma annulus and the side-on smear picture demonstrates the axial behaviour of it. These pictures are composed of three individual registrations from different shots (different brightnesses). The 
slowly developing deformation of the plasmo eventually assumed the form of (two) irregular rings as may be seen on the next slide (fig. 10).

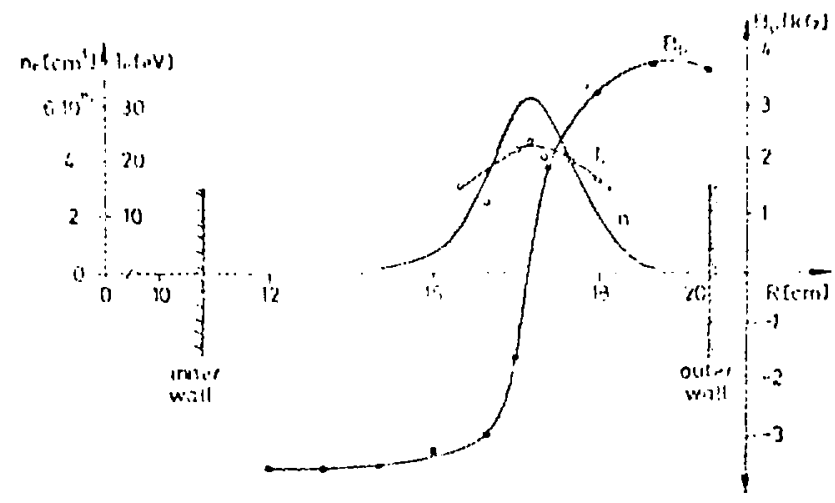

Fig. 8

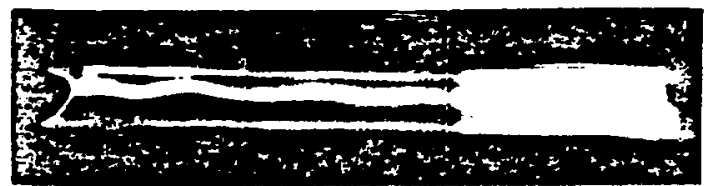

end on
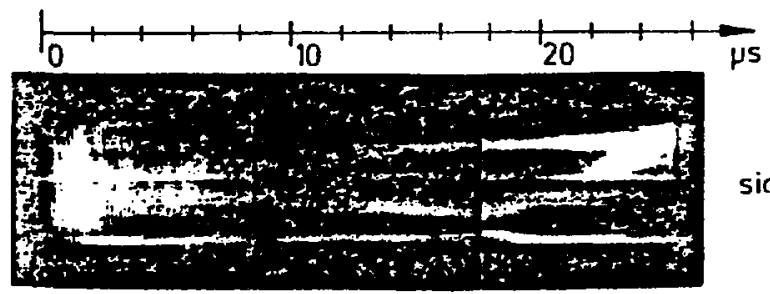

side on

Fig. 9 

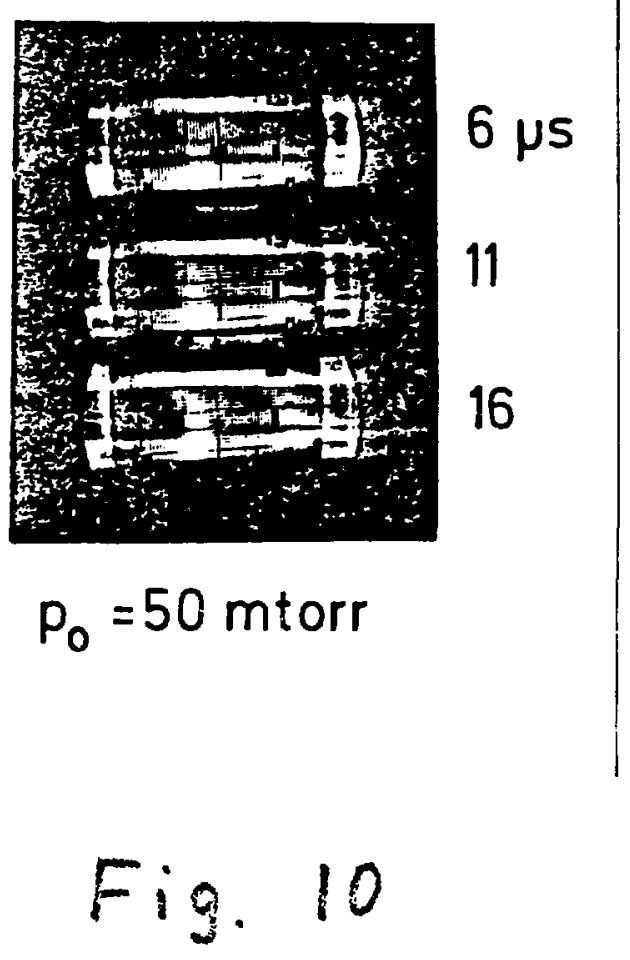

Here are shown side-on framing pictures of a produced plasma annulus. Occasicially there was some incicotion that a plasma helix might have resulted rather than two rings. Superposition of toroidal fields of up to $1 \mathrm{k}$ Gauss in the sheet did not change the time history of the plasma deformations. It was parficularly noticed that the wavelength of the perturbations was always observed to remain constant at $\lambda=30 \mathrm{~cm}$. This could not be changed by taking special care to not excite specific $k$-nodes. For this perticular reason great effort was spent to avoid any external perturbotion of the cenfiguration and to achieve good homageneity and low impurity levels (0.1\% $-0.2 \%$ of axygen in the main discharge) in the preionization plasma.

No rotational WHD-modes were detected in the experiment. For the identification of these perturbatians their growth times $\tau$ (deduced from the times $\tau_{0}$ when the deformation reached the wall, assuming an exponential growth and an initial perturbation of $f / 101$ ware rompared with the sheet-thickness $f$. 
The resu!t is plotted in fig. 11. One reconnizes a quadratic depondency of the

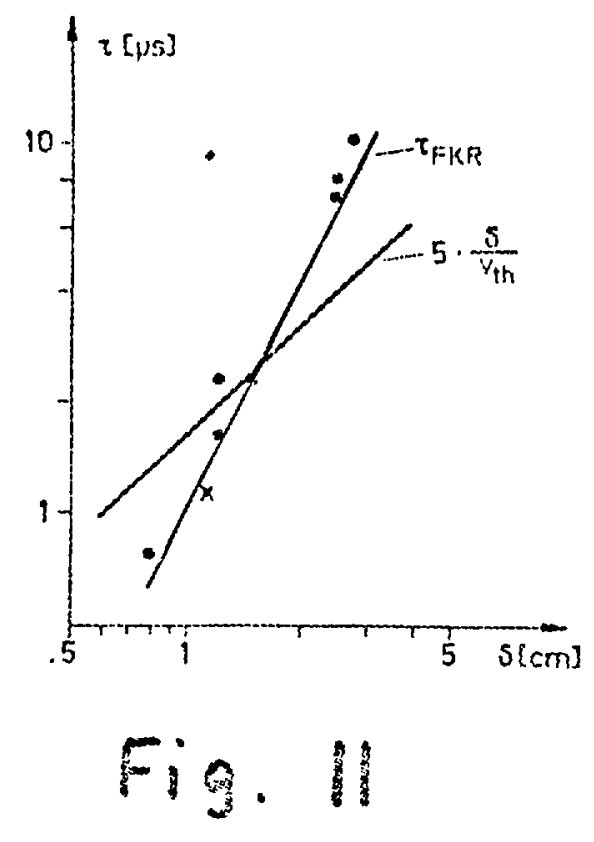

growth times $\tau$ on the sheet-thickness $\delta$. The experimental results are in very good agreement with the FKR-theory for resistive tearing modes, if the experimental finding of constant wavelength, $\lambda=30 \mathrm{~cm}$, is considered:

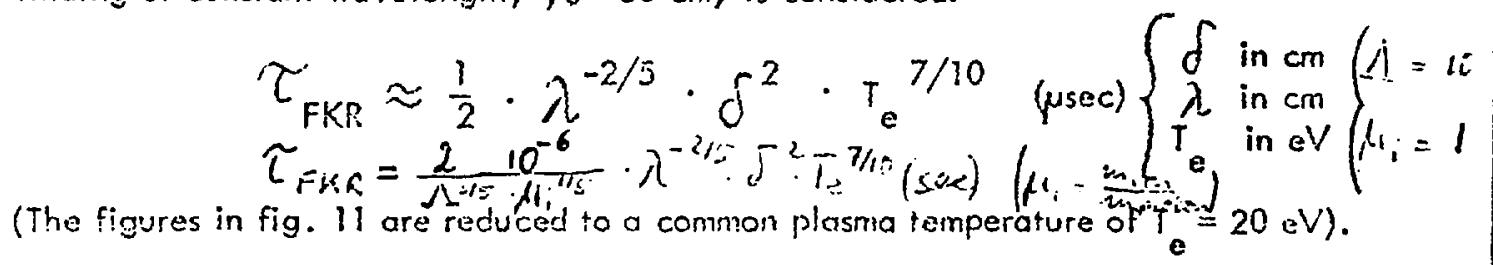

The reason for the constancy of the experimentally abserved wovelength is that these modes are enforced by the periodicity condition of the experiment. We note that the fastest growing mode should develop with a wovelength:

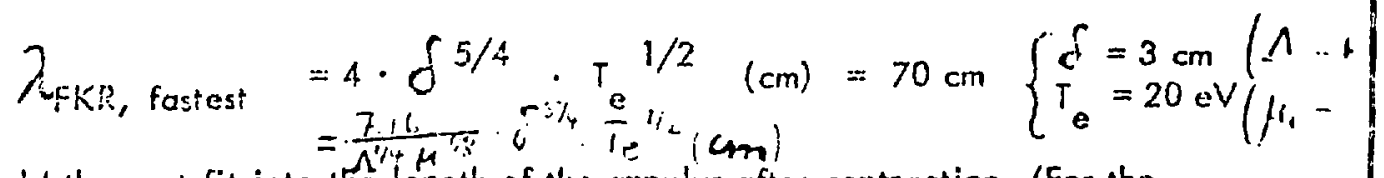

and would thus not fit into the length of the annulus after contraction. (For the fastest growing mode results, as mentioned before: 


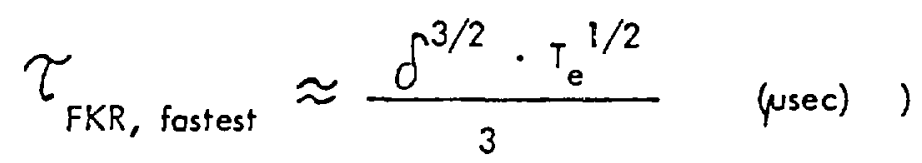

The excellent agreement between the experimental and the theoretical (FKR) growth times, however, should not be overvalued regarding the inherent simplifications in the application of the theory and in the evaluation (e.g. evaluation of $\tau$ in the non-linear regime of a growing perturbation). Nevertheless, it may be taken as a strong indication that the observed gross destruction of the plasma annuli result from resistive tearing mede instabilities.

Further shown in fig. 11 is a comparison of the experimental growth times with the sound transit time multiplied by five. Obviously the plasma lifetime was up to ten times longer than the characteristic growth time for MHD-instabilities. The nonappearance of such MHD-modes during the time of observation do, however, not yet ensure unambigeously the existence of an enhanced stability of elongated cross sections against MHD-modes. It cannot be ruled out for the experiments that at the relatively low temperatures the corresponding initial perturbations are blurred by abundant plasma streaming across the flux surfaces and along the separatrix after diffusion out of the annulus.

Similar experiments at distinctly higher plasma energies are, therefore, necessary to rule out this uncertainty and to arrive at safe statements on the effect of elongated cross sections on the MHD-stability behaviour of toroidal z-pinches. Corresponding plans had to be abandoned in Gorching in fovour of the other Belt-Pinch activities. 
(1) Eberhogen, A., H. Glaser:

Studies on Macroinstabilities in a Theta Pinch with Antiparallel

Magnetic Field

Nucl. Fusion 4 (1964) 296

(2) Eberhagen, A., H. Glaser:

Time and Space-Resolved Electron Densities in a Theta Pinch at Various

Distances along the Discharge Axis

Z. Naturforsch. 20a (1965) 1268

(3) Bodin, H.A.B.:

Observations of Resistive Instabilities in a Theta Pinch

Nucl. Fusion 3 (1983) 215

(4) Furth, H.P., J. Killeen, M.N. Rosenbluth:

Finite-Resistivity Instabilities of a Sheet Pinch

Phys. Fluids 6 (1963) 459

(5) Kalek, A., L. Könen, P. Noll, K. Siguta, F. Waelbroek, K. Watanabe,

H. Wituiski :

Limitation of the Confinement of Plasma in a Linear Theta Pinch with

Trapped Reverse Magnetic Field

Conf. Plasma Phys. and Contr. Nucl. Fusion, Novosibirsk, Vol. II (1968) p. 581

(6) Könen, L., P. Noll, F. Woelbroek, H. Witulski :

The $m=0$ Tearing Mode Instability in a Linear Theta Pincin with Trapped

Reverse Magnetic Field

Europ. Conf. Plasma Phys. and Contr. Fusion, Rome (1970) p. 41

(7) Alidieres, M., R. Aymor, P. Jourdan, F. Koechlin:

Experimental Study of a Current Sheet

Plosma Phys. 10 (1968) 841 
(8) Eberhagen, A., W. Grossmann:

Thetapinch Experiments with Trapped Antiparallel Mageetic Fields

Z. Phys. 248 (1971) 130

(S) Kolek, A. :

Tearing Mode Instabilities of a Rotating Plasmo with Holl-Effect

5th Europ. Conf. on Conir. Fusion and Plasma Phys., Grenoble (1972) p. 30

(10) Es kov, A.G., O.A. Zolotovsky, A.G. Kolygin, R. Kh. Kurtmullaev, Ya.N. Laukhin, A.l. Malyutin, A.l. Markin, A.P. Proshletsov, V.N. Semenov:

Plasma Confinement in a Pulsed System with a Compact Toroidal Configuration

7th Europ. Conf. on Contr. Fusion and Plasma Phys., Lausanne (1975) Vol. 1, p. 55

(11) Laval, G., R. Pellat, M. Vuillemin: Instabilites Electromagnetiques des Plasmas sans Collisions Proc. 2nd int. Conf. on Plasma Phys. and Contr. Nucl. Research, Culham (1965) Vol. 2, IAEA Vienna (1966), 259

(12) Becker, G., A. Eberhagen, O. Gruber, H. Herold, J.M. Peiry, $H$. Röhr, R. Wilhelm, H. Zwicker:

The Garching Belt-Pinch Experiments

Conf. Plasma Phys, and Contr. Nucl. Fusion Research, Tokyo (1974), Vol.ll1, IAEA, Vienna (1975), 47

(13) Eberhogen, A., H. Herold:

Der Belt Pinch mit poloidalem Einschlußfeld

Verhandl. DPG (VI) 10 (1975) 195 